RUNNING HEAD: GROUP SUPERVISION FROM A SMALL GROUP PERSPECTIVE

Group Supervision from a Small Group Perspective.

Siv Boalt Boëthius, Eva Sundin and Marie-Louise Ögren

From the Department of Education, Stockholm University, Sweden (Dr Boalt

Boëthius), the Department of Psychology, Umea University, Sweden (Dr Sundin), and the Department of Psychology, Stockholm University, Sweden (Dr Ögren)

Corresponding author: Siv Boalt Boëthius, PhD, Department of Education, Stockholm, Sweden.

Phone: +4687568025

Fax: +4687566545

email:siv@ped.su.se 


\begin{abstract}
The main objective of this study was to examine a set of independent group variables (group size, gender composition, and supervisory style) in group supervision, and their interrelation with supervisees' and supervisors' view on group interactions, group climate, and attained skill. The study also examined changes over time in supervisees' and supervisors' ratings of group interactions, group climate, and attained skill. Participants were 105 supervisees and 20 supervisors, who worked in 23 supervision groups on basic and advanced training level. Supervisees' and supervisors' experience of group interactions, climate, supervisory style, and attainment of knowledge and skills in the supervision was measured with self-rating scales. Results from hierarchical regression analysis indicate that the group variables measured in this study are interrelated to perceived psychotherapeutic knowledge and skills attainment, group interaction, and group climate. Repeated measures Anova suggested that participants in this study experienced a positive change over time with regard to attainment of knowledge and skills, group interaction, and group climate. Supervisors were more likely to experience a positive change whereas supervisees, and especially supervisees on the basic level, tended to present more stable ratings over time. These data underline the utility and importance of studying group supervision in psychotherapy from a small group perspective.
\end{abstract}

Key words: group supervision, group size, gender composition, supervisory style, group climate, interactions, knowledge and skills attainment, supervisee, supervisor. 


\section{Group Supervision from a Small Group Perspective.}

In many areas of research, for example group supervision in psychotherapy, there is a strong tendency to compare and discuss the study results with other studies focusing on these particular phenomena, rather than with existing research on small group dynamics. This lack of integration has led to a kind of isolation with regard to small group research (Berdahl \& Bouas Henry, 2005) and, moreover, " the group has often been ignored in applied research" (Magen \& Mangiardi, 2005, p. 352). To promote group research across and within different fields it is important to widen the perspective and try to integrate the findings related to specific types of groups to the larger body of small group research. Such comparisons might increase the understanding of how different types of small groups function in naturalistic settings. This study aims to study a number of group variables in the context of group supervision in psychotherapy.

Psychotherapy supervision is a key component of psychotherapy training in many countries (Clarkson, 1998), and it is often described as a highly complex and dynamically interactive situation (e.g., Rønnestad \& Reichelt, 1999). For a long time individual supervision was the predominant form of supervision, but since psychotherapy training courses were established during the 1970s, group supervision seems to have become the most frequently used modality in many countries. However, if this form of psychotherapy supervision is to be used constructively, more knowledge about small group dynamics is of vital importance (Boalt Boëthius \& Ögren, 2003; Hawkins \& Shohet, 2000; Proctor \& Inskipp, 2001). This study will examine the interrelation between group size, group gender composition, and supervisory style on the one hand, and perceived knowledge and skills attainment, group interaction, and group climate on the other. 


\section{Group Size, Gender Composition, and Supervisory Style}

The number of persons in a group has many consequences for various group processes. The available range of knowledge, skills, and abilities increases with increasing size, as well as the sheer number of "hands" that are available for acquiring and processing information (Shaw, 1976). At the same time, the potential number of interpersonal relationships between members increases with group size, and the amount of time available for each member to participate decreases. Although the optimum group size has been estimated to be approximately five persons, this depends on the task, group composition, and other factors such as leadership and organisational context (Brown, 2000; Shaw, 1976).

Prior studies of groups with two to five members (O'Dell, 1968) have indicated that as the size increased group members showed greater disagreement, greater antagonism toward each other, less tension and greater tension release. A reasonable assumption is that groups of four or five allow more space for expressing personal opinions, as well as for finding other group members who can give support. It has also been shown that triads are more adaptable than dyads. Dyads either seem to function fairly well or tend to get stuck more easily than larger groups, as the space for interpersonal relationships is very limited (Smith \& Haythorn, 1972).

Although age and gender of individual group members may be viewed as fairly obvious determinants of behaviours in adult groups, few studies have supported this proposition. This is partly due to the fact that studies of age as a determinant more frequently involve children and adolescents than adults (Shaw, 1976). With regard to gender differences among adults a number of studies indicate that men and women display different types of behaviour (Brown, 2000). However, Wheelan (1996) argues 
that differences in status might be even more important than gender differences. She points out that gender differences are more prominent in laboratory studies, for example, where differences in status tend to be low compared to work groups in naturalistic settings. In order to explore these questions Wheelan (1996) performed a study that sought to find out whether all female or female dominated groups, all male or male dominated groups, and mixed gender groups varied systematically in member perceptions of group development patterns, effectiveness and productivity. A second aim of the study was to examine whether high and low status groups differed significantly on these variables. The results indicated that members' perceptions of group functioning were more similar than different. Where significant differences in perception were noted, group status, as opposed to gender composition, seemed to account for these differences. A conclusion was that when the differences in status among the members of a group are small, differences tend to be attributed to gender differences. Another factor of importance for the composition of groups were the abilities of individual group members, which determined how effectively they could perform the acts that they wished to perform in the group, and this in turn influenced how others reacted to them as group members. In this study, each supervision group contains two to four members of similar age; however, the groups' gender composition varies.

Until a few decades ago, leadership was a structural factor that characterized the group from the very beginning of its life. However, in accordance with research on groups in naturalistic settings, this notion of leadership has been revised to mean that leadership is a process that results from the interactions between the group members and the group leader (Brown, 2000; Granström, 2000; Rioch, 1971). A crucial question regarding leadership is how the leader attains his or her legitimacy. 
Hollander and Julian (1970) suggested that what leaders must do in the early stages of their "reign" is to build up "credit" with the rest of the group. This credit is what gives the leader the subsequent legitimacy to exert influence over these same group members and to deviate from existing norms. Essentially, the more credit one builds up, the more idiosyncratic behaviour will be tolerated by the group. Further studies have shown that these relationships were stronger in high performing groups than in those who worked less effectively (Brown, 2000). In the context of psychotherapy supervision, the supervisor is the assigned leader, which may not always make his or her work easier.

The supervisor's style seems to affect knowledge attainment, group processes, and climate (Boalt Boëthius \& Ögren, 2003; Pertoft \& Larsen, 2003; Reichelt \& Skjerve, 1999; Ögren, Apelman \& Klawitter, 2001; Ögren, Jonsson \& Sundin, 2005). In a study on the interrelation between supervisory style, focus, group climate, and perceived attained skill, differences in supervisory style were related to supervisees' experience of attained skill (Ögren et al., 2005). This study also suggested that values and attitudes, and perception of what topics the supervision focuses on may be important. In a qualitative interview study of 18 pairs of supervisor/supervisee, Reichelt and Skjerve (1999) reported that supervisors who had an accepting, confirming and non-authoritarian style were seen as facilitating development and change. In contrast, supervisors who were experienced as directive and authoritarian contributed to the supervisees' feelings of insecurity and inhibition.

Group Climate, Group Interactions, and Attainment of Knowledge and Skills One of the most important factors when it comes to the question of what makes groups effective has for a long time been conceptualized with terms such as "group 
climate", "group cohesion" and "group culture". The concept of group climate seems to be the most general of the three concepts, and it is often used when evaluating group effectiveness with regard to, e.g., leadership behaviour and group interventions (DeLucia-Waak \& Kalodner, 2005). All three concepts refer to the group as a whole, and which of the terms is used seems to be related mainly to the theoretical frame of reference of the individual author and the context of the group. A number of studies have shown that the group climate in supervision affects the learning climate in various ways (Boalt Boëthius \& Ögren, 2000; Boalt Boëthius, Ögren, Sjøvold \& Sundin, 2005; Pertoft \& Larsen, 2003; Rönnestad \& Reichelt, 1999; Werstlein, 1994; Ögren, Apelman \& Klawitter, 2001). In the present study, the concept of group climate is used to measure to what extent the group meetings are perceived to be characterized by an atmosphere of trust and acceptance, group learning, and/or distrust and rivalry.

One of the first systems for analyzing interactions in small groups was Bales' (1950) Interaction Process Analysis (IPA). The IPA analyzed manifest material primarily, but it was later developed into a more comprehensive model, A System for the Multiple Level Observation of Groups (SYMLOG; Bales \& Cohen, 1979), where latent dimensions involving a certain amount of interpretation were taken into consideration. In a study on role patterns in supervision groups, based on SYMLOG self ratings (Boalt Boëthius \& Ögren, 2000), the results showed that the supervision situation, independent of training level, stimulated specific informal role patterns. Furthermore the study showed that it was just as difficult to find one's role as a supervisee at an advanced level as it had been at the basic level. In a second study, patterns of interaction and group climate were analyzed in 28 psychotherapy supervision groups (Boalt Boëthius, Ögren, Sjøvold \& Sundin, 2004). The findings 
suggested that a certain amount of opposition and conflict in a group might contribute to a more flexible group interaction, and to development and change in the group members. These results were in line with earlier findings (Ögren, Apelman \& Klawitter, 2001), which suggested that, from the supervisees' point of view, experiences of security in the group were not related to perceptions of attained psychotherapy skills. An implication of these findings is that an important task for supervisors is to recognize supervisees' tendency to be "nice" and "pleasing" in the initial phase of supervision. Despite the fact that such behaviour probably is a quite natural phenomenon during the initial phase, the feedback from the supervisor regarding such behaviour might be critical. Supervisors who allow such agreeable behaviour, and at the same time encourage independent ideas and behaviour, may stimulate more effective learning of basic clinical skills.

Empirical studies that help identifying factors that work for or against effective learning are important, since the main task for the supervision group is to facilitate attainment of knowledge and skills needed when working with psychotherapy. Thus, a crucial question is how and to what extent the presence of others helps or hinders individual learning. In general the presence of others implies that people's performance in social tasks is determined by a combination of their own selfexpectations and the potential for evaluation implied by the presence of others performing the same task (Brown, 2000). The importance of constructive and corrective feedback from leaders and other group members has also been emphasized by several authors (Mills, 1984; Morran, Stockton, Cline \& Teed, 1998).

According to Kees and Jacobs (1990), critical elements involved in processing activities that stimulate productivity and learning are good questioning skills, advanced accurate empathy, and an awareness of the focus of the group with the 
ability to hold, shift and deepen the focus. The responsibility for these activities lies mainly with the group leader, whose task it is to stimulate the learning of individual members by means of providing structure, encouraging feedback, conceptualizing group events and processing activities and critical incidents (DeLucia-Waak \& Kalodner, 2005).

Previous studies of group supervision in psychotherapy have indicated that, in favourable circumstances, group supervision can offer a number of new approaches and perspectives regarding supervisory work, and thereby contribute to learning. The importance of the group as a powerful teaching instrument is emphasized both by supervisors and supervisees (Boalt Boëthius \& Ögren, 2000). Ögren and Jonsson (2003) found that group supervision at the basic training level had a distinct and beneficial effect upon the development of the supervisee's psychotherapeutic skills. Under less favourable circumstances, however, the group situation sometimes gives rise to increased feelings of vulnerability, feelings of shame, and defensive attitudes among the group members (Glickauf-Hughes \& Frye-Campbell, 1991; Ögren et al., 2001).

\section{Changes over Time}

A review of the research on group development suggested that groups move through five phases (Wheelan, 2005) or levels of gratification (Mills, 1984). The initial level focuses on issues of inclusion, dependency and immediate gratification. The next level can be described in terms of struggles over autonomy and status, and basic structures for work, which are prerequisites for cohesion and cooperation. The third level is marked by the development of trust and negotiations regarding goals and divisions of labour. The fourth level implies a work phase, characterized by an 
increase in task orientation and open exchange of feedback and information. Wheelan (2005) suggested that groups that have a distinct ending point experience a fifth phase characterized by feelings around ending, while Mills (1984) viewed the fifth level of gratification as a time for growth and reproduction.

In a study of the development of role patterns in supervision groups (Boalt Boëthius \& Ögren, 2000), the results showed that, over time, the supervisees and supervisors experienced that they gradually became close to each other, and, in addition, the supervisees felt that their position in the group changed in a positive direction. Empirical studies of differences in perceived knowledge attainment and group interaction (Sundin \& Ögren, submitted b; Ögren \& Sundin, 2005) and group climate (Sundin \& Ögren, submitted a) in supervisees admitted by an interview and by the traditional procedure respectively suggested that both groups of supervisees attained a substantial amount of knowledge, developed more stable and mature relations to the supervisor and peers, and a more beneficial group climate over time. Supervisees who were admitted by an interview demonstrated a significantly greater change in all three respects.

The purpose of this study was to examine if group characteristics (group size, group gender composition, supervisory style) together with level of training (basic/advanced) can predict perceived knowledge and skill attainment, group interaction (relation to the supervisor and relation to the peers in the supervision group), and group climate in the latter part of the psychotherapy training. In addition, the four categories' (basic level supervisees, basic level supervisors, advanced level supervisees, and advanced level supervisors) perception of supervisees' knowledge attainment and group interaction, and group climate in the supervision situation, will also be compared. 
Specifically, the following questions were addressed: Are group characteristics (group size, group gender composition, and supervisory style) together with level of training (basic/advanced) related to supervisees' and supervisors'

1. perception of the psychotherapeutic skill that supervisees attained in the final part of supervision?

2. perceived group interaction in the supervision situation in the final part of supervision?

3. perceived group climate in the supervision situation in the final part of supervision? And

4. are there differences over time between supervisor and supervisee perceptions of the psychotherapeutic skill that supervisees attained; the group interaction; and the group climate in the supervision?

\section{Method}

\section{$\underline{\text { Participants }}$}

Participants in this study were supervisees and supervisors in courses at basic and advanced (psychotherapy training and supervisor training courses) psychotherapy training levels. In all, 105 supervisees and 20 supervisors participated; 61 supervisees and 7 supervisors who worked in 18 supervision groups were on the basic training level, and 44 supervisees and 13 supervisors who worked in 15 supervision groups were on the advanced training level.

Demographic data for the supervisees are tabulated in table 1. As is shown in table 1 , the supervisees on the advanced level were older compared to those on the basic level, and this difference was significant $(\mathrm{t}(97)=14.21, \mathrm{p}<.001)$. In consequence 
with the age difference, the advanced trainees had more work experience compared to the beginners. Table 2 shows that the majority of supervisors on both training levels were women. The majority of the supervisors had many years of experience of working as group supervisors in psychotherapy within an educational setting. All supervisors had completed a two-year training program in psychotherapy supervision.

Tables 1 and 2 about here

\section{$\underline{\text { Supervision Groups }}$}

On the basic training level, the supervisors generally had more than one supervision group $(M=3$, median $=2)$. On the advanced training level, 13 supervisors had one supervision group each and two supervisors had two groups. Each group contained between 2 and 4 supervisees. On the basic level, $83 \%$ contained 4 supervisees and the remainder contained 3 supervisees. On the advanced level, $80 \%$ of the groups contained 3 or 4 supervisees, and the rest contained 2 supervisees. See table 3.

Table 3 about here

Almost half of the groups (44\%) on the basic training level had an equal number of male and female supervisees, 4 groups (23\%) contained both genders with a single male/female supervisee, and the remaining groups (33\%) contained only female supervisees. On the advanced level, two groups (13\%) contained an equal number of male and female supervisees, 8 groups ( $53 \%$ ) contained both genders but only one male/female supervisee, and five groups (33\%) contained only female supervisees. 


\section{$\underline{\text { The Training Programs }}$}

The goals and content of the program, evaluation procedures and time frames for the students' treatment and supervision work, were clearly defined. The supervision groups were formed by the program's administrative management (director, course coordinator and supervisors). The supervisors participated in regular supervisor meetings arranged by the administrative management. These meetings were arranged for discussing various events and situations that arise during supervision. Evaluations of both individual students and supervision groups were made continually and discussed in the supervisor staff group together with the course administration.

\section{$\underline{\text { Basic level }}$}

The basic level was represented by a psychotherapy training course included in the fiveyear academic program for psychologists (Stockholm University) and a corresponding course given at a university affiliated professional psychotherapy training unit (The St. Lukas Institute). These programs were based on psychodynamic theory. As part of the basic level program the supervisees obtained their first experience of working with an adult patient in individual psychotherapy, one session per week. The students participated in group supervision two hours per week over a period of eighteen months. The psychotherapy supervision aimed at facilitating the learning process with regard to both the clinical work and the theoretical understanding of this work, and to help the supervisee to develop her or his professional role as a psychologist.

\section{$\underline{\text { Advanced level }}$}

The advanced training level included a) a postgraduate training program for psychotherapists given at a university affiliated professional psychotherapy training 
unit (The St. Lukas Institute), and b) a postgraduate training program in psychotherapy supervision given at two different university affiliated professional psychotherapy training units (The St. Lukas Institute and The Erica Foundation). The advanced programs were part-time programs with a psychodynamic orientation.

The supervisees had one or more adult patient in individual psychotherapy, one session per week, and participated in group supervision two hours per week over two years. The psychotherapy supervision aimed at facilitating the learning process with regard to both the clinical work and the theoretical understanding of this work, and to help the supervisee to develop her or his professional role as a psychotherapist. The goal of the training was to award the trainees with a licensure as authorized psychotherapists.

The postgraduate training program for psychotherapy supervisors aimed at training experienced psychotherapists in their work as supervisors for less experienced colleagues. The program required that the supervisor trainees worked individually with a supervisee who treated a patient in individual psychotherapy. The supervisor trainees also received supervision in small supervision groups. The training aimed to facilitate the trainees' understanding of the supervision process and the role as a psychotherapy supervisor. The supervision groups met once a week for two hours over a period of two years.

\section{$\underline{\text { Measurement Instruments }}$}

Quantitative data from questionnaires developed by a Swedish research project on group supervision in psychotherapy (for details, see Ögren \& Sundin, 2004) were used in this study. These questionnaires were constructed in two versions, the Supervisee and the Supervisor Questionnaires, to assess the supervisee's attained 
psychotherapy knowledge and skills; relation to the supervisor and relation to the supervision group; perceptions of group climate; and supervisory style.

\section{Attained psychotherapeutic knowledge and skills}

A scale which measures perceptions of attained psychotherapy knowledge was constructed from 7 items (e. g., "Was able to integrate theoretical knowledge and practical work"). A previous study (Ögren \& Sundin, 2005) showed that the factor solution was stable and that the scale had acceptable internal consistency $(\alpha=.82)$.

\section{Group interaction in group supervision}

A self-rating scale with two subscales that measures relation to the supervisor and relation to the supervision group, respectively has been constructed (Ögren \& Sundin, 2005). In the initial study, acceptable alphas were obtained for the two subscales ( $\alpha=$ $.88 ; \alpha=.87)$.

\section{Group climate in group supervision}

A rating scale with 23 items, Group Climate in Group Supervision (GCGS), was developed to measure perceived group climate in group supervision in psychotherapy. Factor analysis (Sundin \& Ögren, submitted a) resulted in three subscales; Trust and Acceptance, Group Learning, and Distrust and Rivalry. The three subscales had acceptable internal consistencies ( $\alpha=.91, \alpha=.88$, and $\alpha=.85$ respectively).

\section{$\underline{\text { Supervisory style }}$}

For the purpose of undertaking preliminary investigations of supervisors' and supervisors' perceptions of the style that the supervisor used, 12 items were 
formulated (Supportive, Active, Exploring, Engaging, Confronting, Consultative, Theoretical, Structured, Accepting, Empathic, Critical, and Directive). The twelve items were developed through the following procedure. First, 50 items (the 33 items of the SSI and 17 new items) were discussed in a seminar in which the authors along with experienced psychotherapists and group supervisors participated. The goal of this seminar was to select a number of items which dealt with basic supervisory styles. The overlap between items should be minimized, hereby reducing potential intercorrelations across subscales. The list of supervisory styles was also revised in terns of relevance, clarity, simplicity, and ambiguity. Everyone present at the seminar agreed that the twelve supervisory styles met the face and content validity criteria and thus they were retained for further study.

\section{$\underline{\text { Procedures }}$}

The supervisees were asked to rate their perception of attained psychotherapy knowledge and skills, their relation to the supervision group and the supervisor and the supervisor's style. Supervisors were instructed to rate each supervisee in the supervision group(s) concerning their attained psychotherapy knowledge and skill, relation to the supervision group and the supervisor and the supervisor's style. In addition, both supervisees and supervisors rated their experiences of the group climate. The ratings were made on a 5-point rating scale ranging from (1) 'to a very little extent' to (5) 'to a very large extent', at three measurement points; in the initial, middle and final part of the training course.

\section{$\underline{\text { Statistical Analyses }}$}


Multiple regression analysis (MRA) was computed, based on supervisee and supervisor ratings, to examine the predictive potential in group variables (group size and group gender composition), level of training (basic/advanced), supervisors' work experience, and supervisory style at the first measurement, on perceived knowledge attainment, group interaction, and group climate in the latter part of the psychotherapy training. The analyses were performed using the backward elimination method.

Since supervisory style would be included in the MRA's, items pertaining to measure supervisory style were factor analyzed, and possible differences between categories were analyzed.

The statistical analyses used the Statistical Package for the Social Sciences (version 13.0) for PC.

\section{Results}

\section{Supervisory Style}

Since this study aimed to examine whether supervisory style, together with two more group variables, contributed to explain the variance in perceived attained knowledge and skills, group interaction, and group climate, the data on supervisory style collected was used to factor analyze the twelve supervisory style items. The data from the first measurement from the four categories (supervisors and supervisees on basic and advanced training level) that were used in this study were pooled to obtain a sample size $(n=193)$ that was large enough to justify the use of exploratory factor analysis (EFA) (Nunally \& Bernstein, 1994; Stevens, 2002). First, the data was examined using cross tables, scatter plots, and correlations. The twelve items had moderate covariances $(\mathrm{M}=.25, \mathrm{SD}=.07$, range from -.39 to .58$)$. Then principal components analysis was used for extracting factors. Rotation of factors was achieved 
using both varimax and oblique rotation. Almost identical factor solutions were obtained with the different rotation methods: three factors emerged which had factor loadings above $|.50|$ from four items. There was no cross loading. Internal consistencies were acceptable $(\alpha=.84, \alpha=.61$, and $\alpha=.65$ respectively). The bivariate correlations among factors were weak $(r=.04-r=.15)$, which suggested that the three factors were relatively independent from each other. Three subscales were created based on the factors, named Supportive style (exploring, invested, empathic, accepting); Demanding style (confronting, critical, non-supportive, theoretical); and Decisive style (consultative, directive, active, structured).

\section{Attained Psychotherapeutic Knowledge and Skills}

Differences between supervisees' and supervisors' perceived knowledge and skills $\underline{\text { attainment over time }}$

First, basic and advanced level supervisees' and supervisors' ratings of attained knowledge and skills at Measurements 1 and 3 were tested as a within-subjects factor using a General Linear Model Repeated Measures (GLM) procedure with a Greenhouse-Geisser correction when sphericity could not be assumed. The analysis tested the effect of category (basic level supervisor/ basic level supervisee/advanced level supervisor/advanced level supervisee). The sphericity assumption was not met so the Greenhouse-Geisser correction was applied.

The analysis showed that there was a significant difference in perceptions of attained knowledge and skills over time, $\underline{\mathrm{F}}(1,191)=75.558, \mathrm{p}<.001$. The interaction term between ratings of attained knowledge and skills and category (basic level supervisees, basic level supervisors, advanced level supervisees and advanced level supervisors) was also significant, $\underline{\mathrm{F}}(3,191)=9.448, \mathrm{p}<.001$. Figure 1 shows that, 
with one exception, the ratings from the categories are parallel to each other, indicating that the supervisees attained more psychotherapy knowledge and skills in the latter part of the supervision period compared to the initial part. The exception was the average supervisee on the basic level, who presented very similar ratings at the two measurements. Posthoc tests showed that there was no significant difference among the categories.

Figure 1 about here

$\underline{\text { Effect of group variables on perceived knowledge and skills attainment }}$

To examine the contribution of group variables (group size, the group's gender composition, and supervisory style) in accounting for time related changes in perceived attainment of knowledge and skills, multiple regression analysis was performed.

A model was built where ratings at Measurement 1 of perceived knowledge and skills was entered in the first step to control for pre-training levels of this factor. To control for demographic variables (supervisees' gender and age, and supervisors' gender), the supervisee's work experience, and supervisors' work experience (supervisors' previous experience of working as supervisor within educational settings; experience of working as group supervisor), these variables were also entered in the first step. Since the comparative analyses of the groups revealed significant interaction effects of training level (basic, advanced), that variable was entered into the model. Supervisory style subscales (Supportive, Decisive, Demanding) rated by supervisors and supervisees at Measurement 1, and group size and the group's gender composition were added into the equation in the second step. 
The result showed that six variables; supervisees' age and gender, training level, perceived attainment of knowledge and skills at Measurement 1, group size, and group gender composition, contributed to the model's explanatory power (adjusted $\mathrm{r}^{2}$ $=.37, \underline{\mathrm{F}}(7,74)=8.973, \mathrm{p}<.001)$ for perceived attainment of knowledge and skills at Measurement 3. Variables that were statistically significant were supervisees' age ( $=-.43, \mathrm{p}<.006)$ and gender $(\beta=.24, \mathrm{p}<.015)$, training level $(\beta=.60, \mathrm{p}<.001)$, and perceived attainment of knowledge and skills at Measurement $1(\beta=.49, \mathrm{p}<.001)$. The standardized beta coefficients indicated that larger group size and a gender composition with only female supervisees were beneficial for perceived attainment of knowledge and skills. Training level was the strongest predictor of attained knowledge and skills; supervisees who were on the advanced level were perceived to attain more knowledge and skills. Coefficients for supervisees' age and gender indicated that being younger and female was related to knowledge and skills attainment.

\section{Group Interaction in Group Supervision}

Differences between supervisees' and supervisors' perceptions of group interactions $\underline{\text { over time }}$

GLM Repeated Measures was used to test for changes in basic and advanced level supervisees' and supervisors' ratings of 1) relation to supervisor and 2) relation to he supervision group at Measurements 1 and 3. Possible differences between basic and advanced level supervisees' and supervisors' ratings of relation to supervisor were examined. The sphericity assumption was not met so the Greenhouse-Geisser correction was applied. 
The first analysis showed that there was a significant difference in perceived relation to the supervisor over time, $\underline{\mathrm{F}}(1,177)=3.919, \mathrm{p}<.05$. The interaction term between ratings of relation to supervisor and category (basic level supervisees, basic level supervisors, advanced level supervisees and advanced level supervisors) was also significant, $\underline{F}(3,177)=5.647 \mathrm{p}<.001$. Figure 2 shows that the average supervisee on the basic and advanced levels presented similar ratings on Measurement 1 and Measurement 3 while supervisors on both training level gave higher ratings on the final measurement than on the initial measurement.

The second GLM indicated that there was a significant difference over time in ratings of relation to peers in the supervision group, $\underline{F}(1,177)=13.1187 \mathrm{p}<.001$. The interaction term between ratings of relation to peers in the supervision group and categories was also significant, $\underline{\mathrm{F}}(3,177)=5.980, \mathrm{p}<.001$. The average supervisor on both training levels gave lower ratings of the relation to group peers at Measurement 1 than at Measurement 3. Both the supervisees on the basic and the advanced level presented average ratings at the initial and final measurements that were relatively similar. See figure 3 .

Figures 2 and 3 about here

$\underline{\text { Effect of group variables on perceived group interactions }}$

Multiple regression analysis was computed to test the effect of group variables on perceived group interactions (relation to the supervisor and relation to the group peers). The model that was used in the previous analysis was modified so that it could be used to examine group interactions instead of knowledge and skills attainment. Two analyses were performed: in the first analysis, the model's predictive power on 
relation to the supervisor was tested, in the second; the model's predictive power on relation to the supervision group was tested.

The first analysis showed that the model's ability to predict the relation to the supervisor accounted for $25 \%$ of the variance (adjusted $\mathrm{r}^{2}=.25, \underline{\mathrm{F}}(4,80)=8.159,<$ .001 ). Four of the variables were significant (supervisor gender, $\beta=.22, p<.04$, group size, $\beta=.27, \mathrm{p}<.04$, relation to supervisor, Measurement $1, \beta=.47, \mathrm{p}<.001$, supervisor's previous experience of working as a group supervisor, $\beta=.28, \mathrm{p}<.04$ ). The beta coefficients indicated that there was a significant interrelationship between perceptions of good relation to supervisor at the third measurement and larger group size; male supervisor; supervisor had more previous experience of working as a group supervisor; and good relation to supervisor at the first measurement.

The second analysis indicated that four variables contributed to the model's power to predict experiences of the relation to the supervision group (adjusted $r^{2}=.32, \underline{F}(4$, $80)=10.861,<.001)$. The four variables were: ratings of relation to the supervision group at Measurement $1(\beta=.47, \mathrm{p}<.001)$, demanding supervisory style $(\beta=.30, \mathrm{p}<$ $.001)$, supervisee gender $(\beta=.20, p<.05)$, and group gender composition $(\beta=-.16, p$ $<.10)$. The result suggested that good relations to the group peers were related to a supervisor that was experienced to have a more demanding supervisory style, and groups where both genders were represented, with more female than male supervisees.

\section{Group Climate in Group Supervision}


Differences between supervisees' and supervisors' perceptions of the group climate over time

To test the difference between category ratings of group climate over time, measured with the GCGS at Measurements 1 and 3, GLM Repeated Measures was used. Three different analyses were computed to examine differences over time in ratings of the three subscales (Trust and Acceptance, Group Learning, and Distrust and Rivalry, respectively).

The first analysis showed that the difference over time in perceived trust and acceptance (GCGS I) was insignificant. However, statistical significance was obtained for the interaction term between ratings of trust and acceptance and category (basic level supervisees, basic level supervisors, advanced level supervisees and advanced level supervisors), $\underline{F}(3,105)=3.194 \mathrm{p}<.027$. As is shown in figure 4, supervisors on both training level gave higher ratings on the final measurement than on the initial measurement, while supervisees on both training levels presented similar ratings on both measurement points. Between subjects analysis showed that there was one or more significant difference among categories $(\underline{\mathrm{F}}(3,105)=4.418, \mathrm{p}<.006)$. The Tukey-Kramer posthoc test (using an alpha of .02 to control for Type I error; $.05 / 3$ ) showed that advanced level supervisees' ratings were significantly higher compared to basic level supervisees' ratings $(\mathrm{p}<.003)$.

Figure 4 about here

The second analysis examined differences between the four categories over time for their ratings of Group Learning (GCGS II). The results showed that the change over time in ratings of Group Learning was significant $(\underline{F}(1,108)=7.542, p<.007)$. 
The interaction term between ratings of Group Learning and category was also significant $(\underline{\mathrm{F}}(3,108)=6.415, \mathrm{p}<.001)$. The categories' ratings of group learning were similar to their ratings of Trust and Acceptance, i.e., for Group Learning, supervisors on both training level gave higher ratings on Measurement 3 than on Measurement 1, while the ratings presented by both categories of supervisees were on a similar level. In contrast to the ratings of Trust and Acceptance, the two categories of supervisees presented similar ratings of Group Learning.

The repeated measures analysis of supervisees' and supervisors' ratings of Distrust and Rivalry at Measurements 1 and 3 was not significant.

\section{Effect of group variables on perceived group climate}

To assess the interrelationships of the set of measured group variables and perceived group climate at Measurement 3, the regression model that was used in the previous analyses was used. In this analysis, group climate ratings at Measurement 1 were entered in the first step to control for pre-training levels of this factor, together with demographic variables (supervisees' gender and age, and supervisors' gender), the supervisee's work experience, supervisors' work experience (supervisors' previous experience of working as supervisor within educational settings; experience of working as group supervisor), and training level (basic, advanced). Supervisory style (Supportive, Decisive, Demanding) rated by supervisors and supervisees at Measurement 1 was added into the equation in the second step; and group size and the group's gender composition were entered in the third step. Since there are three subscales in the GCGS, a General Linear Model (GLM) multivariate analysis was computed instead of three multiple regression analyses. 
The GLM multivariate analysis showed that, for each of the three subscales (Trust and Acceptance, Group Learning, and Distrust and Rivalry), a significant portion of variance was accounted for by the model (adjusted $\mathrm{r}^{2}=.41, \underline{\mathrm{F}}(11)=7.33, \mathrm{p}=.001$; $.33, \underline{\mathrm{F}}(11)=5.56, \mathrm{p}=.001$; and $.29, \underline{\mathrm{F}}(11)=4.64, \mathrm{p}=.001$, respectively). Thus, the model accounted for between $29 \%$ and $41 \%$ of the variance in GCGS ratings at the third measurement. The multivariate analysis confirmed that group size, along with supervisor gender and experience of working with group supervision, and GCGS ratings at Measurement 1 were significant predictors of GCGS ratings at Measurement 3. Also, the interaction term between group size and gender composition was a significant predictor of Trust and Acceptance at Measurement 3 $(\underline{F}(2)=3.58, p<.03)$. This analysis suggested that groups with four supervisees tended to experience more trust and acceptance when the group contained an equal number of female and male supervisees compared to groups that contained only female supervisees. This relationship was reversed in groups with two supervisees, i. e., more trust and acceptance was experienced in groups that contained only female supervisees compared to groups with both gender (one male and one female supervise). (see figure 5).

Figure 5 about here

\section{Discussion}

The results of the multiple regression analyses (MRA) indicate that the group characteristics measured in this study (group size, group gender composition, and supervisory style) contributed, to a varying extent, to explain the variance in 
perceived psychotherapeutic knowledge and skills attainment, group interaction, and group climate. For example, larger group size was related to perceived good relations to the supervisor and the group peers, and also to a subjectively experienced good group climate. The findings suggested that, dependent on group size, group gender composition has different impact on group climate. Thus, groups with four supervisees tended to experience more trust and acceptance, when the group contained an equal number of female and male supervisees compared to groups that contained only female supervisees. In groups with two supervisees, this relationship was reversed so that more trust and acceptance was experienced in groups that contained only female supervisees compared to groups with both genders (one male and one female supervise). This finding could be interpreted to suggest that a two times two gender composition provides sufficient space for the supervisees to express differences in opinion, expose their own vulnerabilities, and seek support from the supervisor and other group members. At the same time the balanced number of female and male supervisees might contribute to optimize the group's potential to perform well. Thus, an implication of this result is that it might be preferable to put together groups with four rather than two or three members. These findings are in accordance with previous study results (Brown, 2000).

This study also suggests that supervisee age and gender impact on perceived attainment of knowledge and skills during supervision so that female and younger supervisees were experienced to attain more knowledge and skills compared to male and older supervisees. It is noteworthy that, in line with Wheelan's (1996) proposition, higher status (in this case advanced training level) is even more important than gender. Then again, the majority of supervisees and supervisors are women and thus it seems likely that the culture implicit in psychotherapy training favours women 
rather than men. This supposition agrees with previous studies of attitudes towards psychotherapy in men and women, respectively (Jacobsson, 2005; Sandell et.al., 2000). There seems to be a need for a greater awareness of gender differences concerning attitudes and needs in the field of psychotherapy and psychotherapy supervision.

In this study, supervisory style accounted for a portion of variance in one variable, namely relations to the group peers. The MRA suggested that good relations to the group peers were related to a supervisor that was experienced to have a more demanding supervisory style. This might indicate that the supervisees tend to get closer to each other when the supervisor is perceived as more demanding. The new measure of supervisory style is promising, however, the rating scale is too brief (although acceptable given the small number of items in the scales, internal consistencies in the lower end).

The results of the analyses of differences over time showed that the general trend was that there was a significant change over time in experience of attained knowledge and skills, group interaction, and group climate. The change over time is mainly found in the supervisors' ratings, while supervisees, and especially supervisees on the basic level, tended to present similar ratings at the two measurement points. For example, the supervisors on both training levels perceived that the supervisees attained more psychotherapy knowledge and skills in the latter part of the supervision period compared to the initial part. Supervisees on the advanced level reported comparable perceptions, while supervisees on the basic level seem to have almost identical views on their knowledge and skills attainment in the beginning and the end phase of the supervision. 
While it is reasonable to view the supervisors' ratings of their supervisees' clinical expertise as a relatively accurate estimation, should supervisees' ratings be considered similarly? Recently, the value of self-evaluation of one's clinical knowledge and competencies has been emphasized by many proponents, as a means to summarize areas where more training is needed (Bose, Oliveras, \& Edson, 2001) or a complementary route to attaining more knowledge and skills (Belar et al., 2001). However, beginner psychotherapists who receive supervision for the first time may not be able to make accurate self-appraisals, which could explain the difference between supervisee and supervisor ratings on the basic level. In a previous study, we suggested that the beginner supervisees' self-appraisals rather should be seen as an indicator of the supervisee's experience of mastering the role of a beginner psychotherapist and supervisee rather than an assessment of attained psychotherapeutic competencies (Ögren, Jonsson, \& Sundin, 2005). If this is the case in this study, the results suggested that the average basic level supervisee felt relatively comfortable during the whole period of supervision.

While a number of changes over time were measured, there was only one significant difference among categories (basic level supervisees and supervisors, and advanced level supervisees and supervisors), i.e., between supervisees on basic level and advanced level, respectively. Supervisees on the advanced level perceived that the group climate in the supervision group was characterized by more trust and acceptance compared to the beginner supervisees. The overall results of this study points to a general satisfaction with the work situation in the groups, both among supervisees and supervisors. Therefore, it is important to remember that the study findings may not be generalizable to supervision groups where supervisees and/or their supervisors are less content with their work situation. 
A general conclusion is that studies of group supervision in psychotherapy from a small group perspective can contribute with valuable information to the field.

\section{Acknowledgement}

This research was supported by grant 721-2002-2586, The Swedish Research Council. 


\section{References}

Bales, R. F. (1950). Interaction Process Analysis: A method for the study of small groups. Chicago, IL: University of Chicago Press.

Bales, R. F., \& Cohen, S .P. (1979). SYMLOG: A System for the Multiple Level Observation of Groups. New York: Free Press.

Belar, C. D., Brown, R. A., Hersch, L. E., Hornyak, L. M., Rozensky, R. H., Sheridan, E. (2001). Self assessment in clinical health psychology: A model for ethical expansion of practice. Professional Psychology: Research and Practice, 32, $135-141$.

Berdahl, J., \& Bouas, H. K., (2005). Contemporary issues in group research: The need for integrative theory. In S. Wheelan (Ed.), The handbook of group research and practice (pp. 19-38). London; Sage Publications.

Boalt Boëthius, S. \& Ögren, M-L. (2000). Role patterns in group supervision. The Clinical Supervisor, 19 , 45-69.

Boalt Boëthius, S. \& Ögren, M-L. (2003). Grupphandledning. Den lilla gruppen som forum för lärande. [Group supervision. The small group as a forum for learning]. Stockholm: Mareld/Ericastiftelsen.

Boalt Boëthius, S., Ögren, M-L., Sjøvold, E., \& Sundin, E. (2005). Experiences of group culture and patterns of interaction in psychotherapy supervision groups. The Clinical Supervisor, 23, 101-120.

Bose, S., Oliveras, E., \& Edson. W. N. (2001). How can self-assessment improve the quality of healthcare? Operations Research Issue Paper 2 (4). Retrieved February 7, 2004 from http://www.dec.org/pdf_docs/PNACN247.pdf

Brown, R. (2000). Group processes. Dynamics within and between groups. Oxford: Blackwell Publishers. 
Clarkson, P. (1998). Supervision. Psychoanalytic and Jungian perspectives. London: Whurr Publishers.

DeLucia-Waak, J. L., \& Kalodner, C. R. (2005). Contemporary issues in group practice. In S. Wheelan (Ed.), The handbook of group research and practice. (pp. 65-84). London; Sage Publications.

Glickauf-Hughes, C., \& Frye-Campbell, L. (1991). Experiential supervision: Applied techniques for a case presentation approach. Experiential Supervision, 28, 625-635.

Granström, K. (2000). Dynamik i arbetsgrupper. Om grupprocesser på arbetet. [Dynamics in work groups]. Lund: Studentlitteratur.

Hawkins, P., \& Shohet, R. (2000). Supervision in helping professions (2nd ed.). Philadelphia: Open University Press.

Hollander, E. P. \& Julian, J. W. (1970). Studies in leader legitimacy, influence, and innovation. In L. Berkowitz (Ed.), Advances in experimental social psychology. Vol. 5 (pp. 33-69). New York: Academic Press.

Jacobsson, G. (2005). On the threshold of adulthood: Recurrent phenomena and developmental tasks during the period of young adulthood. Stockholm: Intellecta Docysys.

Kees, N. L. \& Jacobs, E. (1990). Working with groups: Conducting more effective groups: How to select and process exercises. Journal for Specialists in Group Work, 15, 21-29.

Magen, R. H., \& Mangiardi, E. (2005). Groups and individual change. In S. Wheelan (Ed.), The handbook of group research and practice. (pp. 351-362). London: Sage Publications

Mills, T. M. (1984). The sociology of small groups. New Jersey: Prentice-Hall, Inc. 
Morran, D.K., Stockton, R., Cline, R.J. \& Teed, C. (1998). Facilitating feedback exchange in groups: Leader interventions. Journal for Specialists in Group Work, $23,257-268$.

O’Dell, J. W. (1968). Group size and emotional interaction. Journal of Personality and Social Psychology, 8, 75-78.

Pertoft, M., \& Larsen B. (2003). Grupphandledning med yrkesverksamma i människovård. [Group supervision for professionals in treatment units]. Stockholm: Liber AB.

Proctor, B., \& Inskipp, F., (2001). Group supervision. In J. Scaife (Ed.). Supervision in mental health professions: A practioner's guide. (pp. 99-121). London: Sage Publications.

Rando, R. A. (2001). Adaptive supervision in counselor training. The Clinical Supervisor, 20, 173-182.

Reichelt, S., \& Skjerve, J. (1999). En kvalitativ undersøkelse av veiledning i Norge [A qualitative study of supervision in Norway]. In M. H. Rønnestad \& S. Reichelt (Eds.). Psykoterapiveiledning. [Psychotherapy supervision] (pp. 247-266). Oslo: Tano Aschehoug.

Rioch, M. (1971).” All we like sheep - “(Isaiah 53:6): Followers and leaders. Psychiatry, 34, 258-273.

Rønnestad, M. H., \& Reichelt, S., (Eds.), (1999). Psykoterapiveiledning. [Psychotherapy supervision]. Oslo: Tano Aschehoug.

Sandell, R., Blomberg, J., Lazar, A., Carlsson, J., Broberg, J., \& Schubert, J. (2000). Varieties of long-term outcome among patients in psychoanalysis and long-term psychotherapy. A review of findings in the Stockholm Outcome of Psychoanalysis 
and Psychotherapy Project (STOPPP). International Journal of Psychoanalysis, 81, 921-942.

Shaw, M. E. (1976). Group dynamics: The psychology of small group behavior. New York: McGraw-Hill Book Company.

Smith, S., \& Haythorn, W. W. (1972). Effects of compatibility, crowding, group size, and leadership seniority on stress, anxiety, hostility and annoyance in isolated groups. Journal of Personality and Social Psychology, 22, 67-79.

Stevens, J. (2002). Applied multivariate statistics for the social sciences (4th Edition). Mahwah, NJ: Lawrence Erlbaum Associates.

Sundin, E. C., \& Ögren, M-L. Supervisees' and supervisors' experiences of group climate in group supervision in psychotherapy. Effects of admission procedure. Submitted a).

Sundin, E., \& Ögren, M-L. Implications of an individualized admission selection procedure for professional programmes in psychology. Submitted b).

Toothaker, L. E. (1993). Multiple comparison procedures. Newbury Park, CA: Sage.

Wheelan, S. (1996). Effects of gender composition and group status differences on members perceptions of group developmental patterns, effectiveness, and productivity. Sex Roles, 34, 665-686.

Wheelan, S. (2005). (Ed.). The handbook of group research and practice. London; Sage Publications.

Werstlein, P.O. (1994). Fostering counselors' development in group supervision. Greensboro, NC: ERIC Clearinghouse on Counseling and Student Services (ED372351).

Ögren, M-L., Apelman, M., \& Klawitter, A., (2001). The group in psychotherapy supervision. The Clinical Supervisor, 20, 147-175. 
Ögren, M-L., Jonsson, C-O., \& Sundin, E.C. (2005). Group supervision in psychotherapy. The relationship between focus, group climate, and perceived attained skill. Journal of Clinical Psychology, 61, 373-388.

Ögren, M-L., \& Sundin, E. C. (2005). Intervjuer som prognosinstrument för studieframgång. [Interview as an instrument for predicting college success]. Nordisk Psykologi, 3, 271-288. 
Figure Captions

Figure 1. Mean ratings of attained knowledge and skills at Measurements 1 and 3 for basic and advanced level supervisees and supervisors

Figure 2. Mean ratings of relation to supervisor at Measurements 1 and 3 for basic and advanced level supervisees and supervisors

Figure 3. Mean ratings of relation to group peers at Measurements 1 and 3 for basic and advanced level supervisees and supervisors

Figure 4. Mean ratings of trust and acceptance (GCGS I) at Measurements 1 and 3 for basic and advanced level supervisees and supervisors

Figure 5. Group size by mean ratings of trust and acceptance (GCGS I) at Measurement 3 for basic and advanced level supervisees and supervisors 
Estimated marginal means of ratings of knowledge and skills attainment

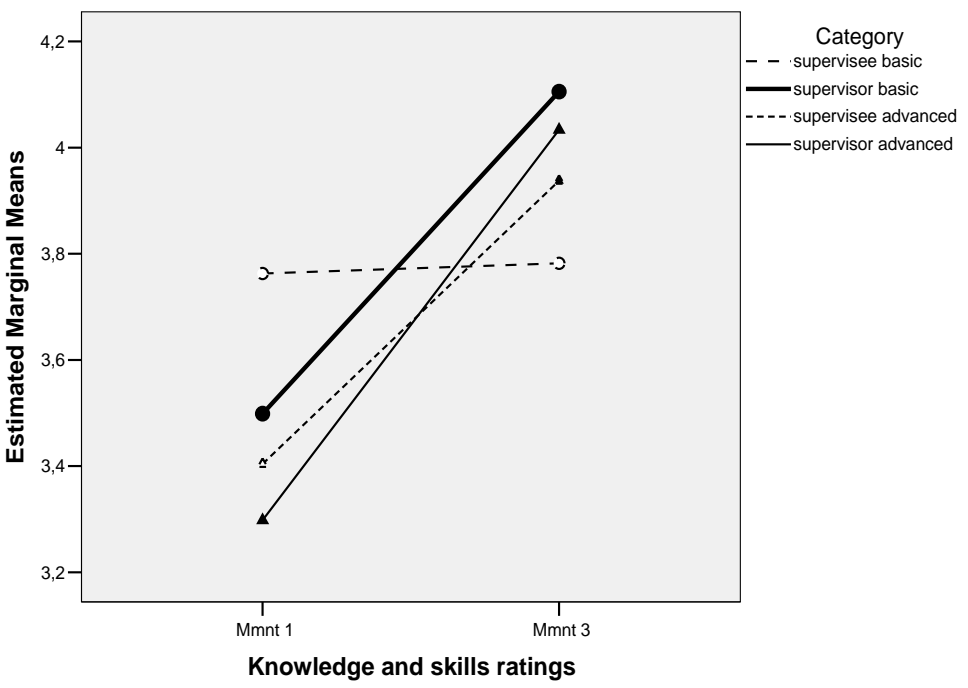

Figure 1. Mean ratings of attained knowledge and skills at Measurements 1 and 3 for basic and advanced level supervisees and supervisors 


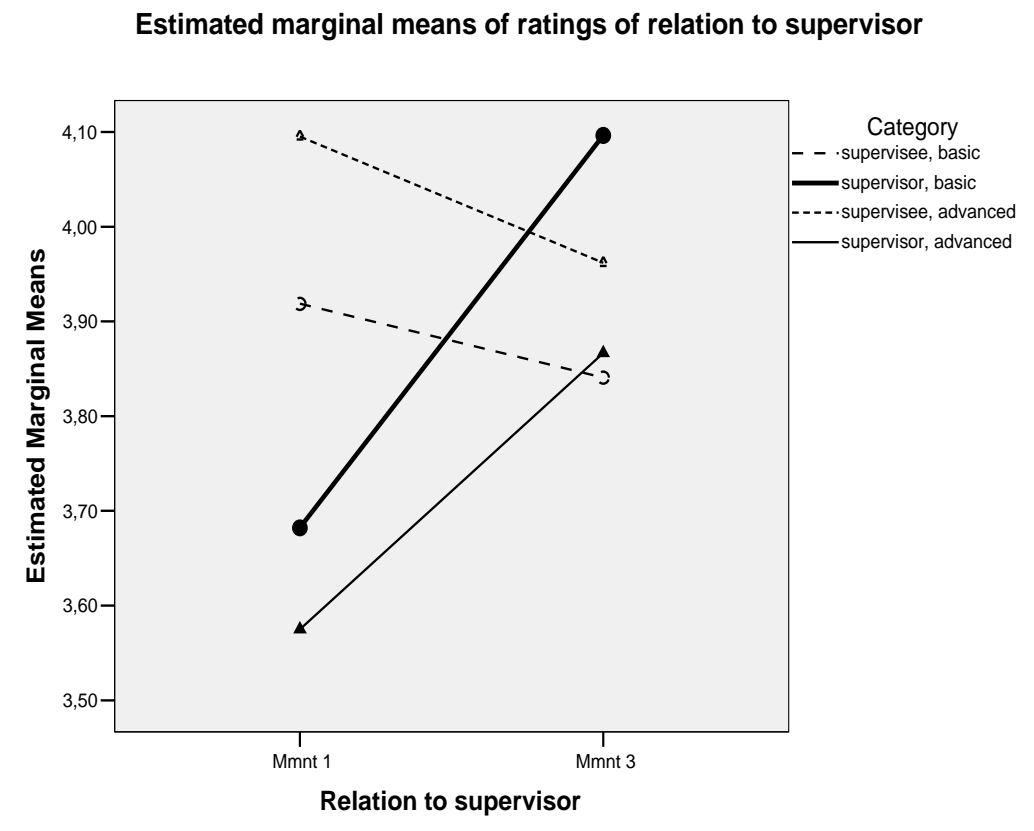

Figure 2. Mean ratings of relation to supervisor at Measurements 1 and 3 for basic and advanced level supervisees and supervisors 
Estimated marginal means of ratings of relation to group peers

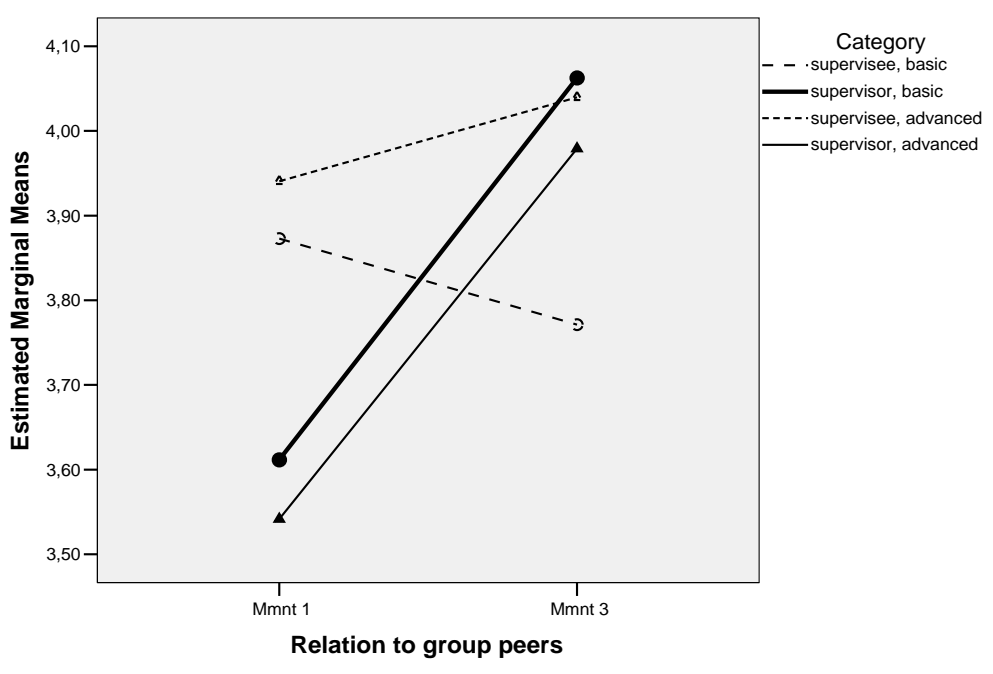

Figure 3. Mean ratings of relation to group peers at Measurements 1 and 3 for basic and advanced level supervisees and supervisors 
Estimated marginal means of ratings of trust and acceptance

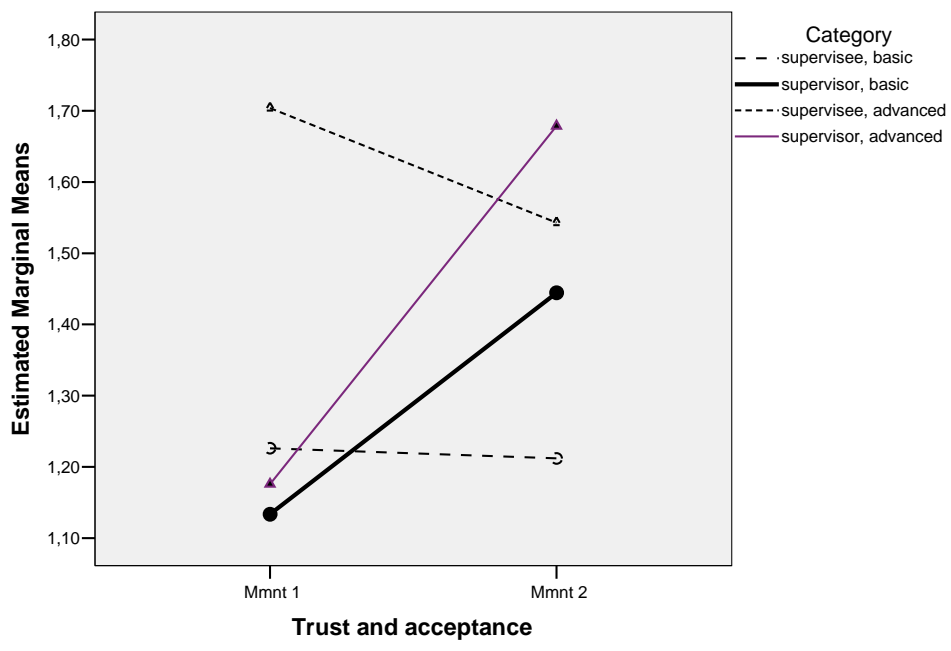

Figure 4. Mean ratings of trust and acceptance (GCGS I) at Measurements 1 and 3 for basic and advanced level supervisees and supervisors 
Estimated marginal means of Trust and acceptance, Measurement 3

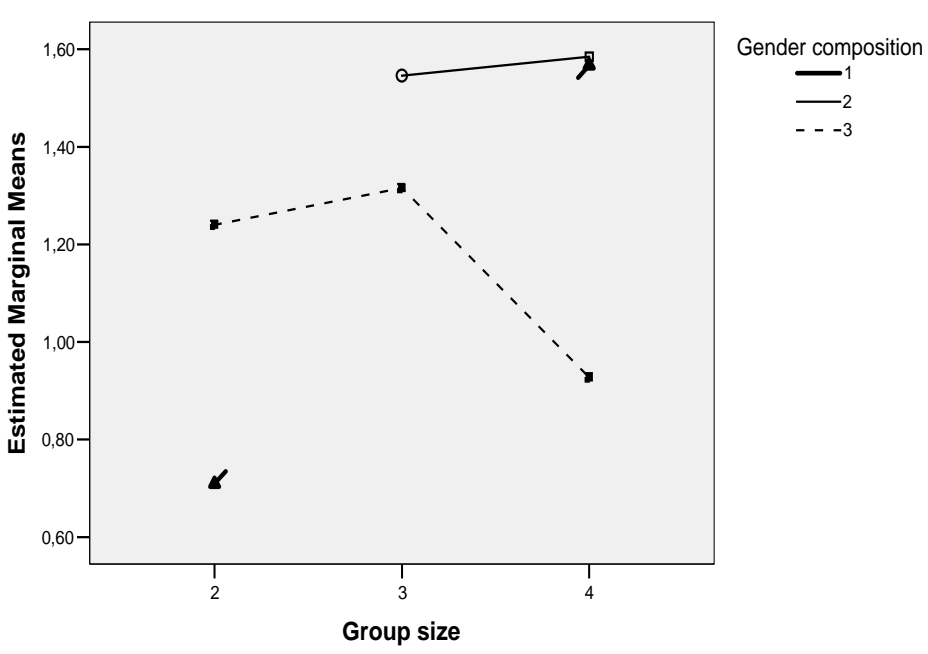

Figure 5. Group size by mean ratings of trust and acceptance (GCGS I) at Measurement 3 for basic and advanced level supervisees and supervisors Note. For Group size, $2=2$ supervisees; $3=3$ supervisees; $4=4$ supervisees. For Group gender composition, 1 = equal number of female and male supervisees; $2=$ both female and male supervisees, however there is an unequal number of female and male supervisees; 3 = only female supervisees.

(Data for groups with an equal number of female and male supervisees are represented by a data marker, not by a line, since none of these groups contained 3 supervisees). 
Table 1. Demographic data for the supervisees

\begin{tabular}{|c|c|c|c|c|c|}
\hline \multirow[t]{2}{*}{ Training level } & \multirow{2}{*}{$\begin{array}{l}\text { Age } \\
M(S D)\end{array}$} & \multirow[t]{2}{*}{ Gender } & \multicolumn{3}{|c|}{ Work experience } \\
\hline & & & 1 year & $2-10$ years & $>10$ years \\
\hline $\begin{array}{l}\text { Basic } \\
(n=61)\end{array}$ & $32.80(6.01)$ & $72 \%$ female & $17 \%$ & $73 \%$ & $10 \%$ \\
\hline $\begin{array}{l}\text { Advanced } \\
(n=44)\end{array}$ & $49.55(5.16)$ & $68 \%$ female & & $14 \%$ & $86 \%$ \\
\hline
\end{tabular}


Table 2. Demographic data for the supervisors

\begin{tabular}{llllllll}
\hline Training & Gender & \multicolumn{2}{l}{ Supervisory experience } & \multicolumn{2}{l}{ Supervisory experience } \\
level & & from an educational context & from a group context \\
& & $1 \mathrm{y}$ & $1-11 \mathrm{y}$ & $>11 \mathrm{y}$ & $1 \mathrm{y}$ & $1-11 \mathrm{y}$ & $>11 \mathrm{y}$ \\
& & & & & & & \\
\hline Basic & $78 \%$ female & $11 \%$ & $22 \%$ & $67 \%$ & - & $20 \%$ & $80 \%$ \\
$(\mathrm{n}=20)$ & & & & & & & \\
Advanced & $75 \%$ female & $10 \%$ & $50 \%$ & $40 \%$ & $10 \%$ & $50 \%$ & $40 \%$ \\
$(\mathrm{n}=13)$ & & & & & & & \\
\end{tabular}


Table 3. Number of supervisees in the supervision groups at basic and advanced level Training level Number of supervisees in the supervision group

\begin{tabular}{llll}
\hline & 2 supervisees & 3 supervisees & 4 supervisees \\
\hline Basic & $0(0 \%)$ & $3(17 \%)$ & $15(83 \%)$ \\
$(\mathrm{n}=18)$ & & & \\
Advanced & $3(20 \%)$ & $8(53 \%)$ & $4(27 \%)$ \\
$(\mathrm{n}=15)$ & & & \\
Total & $3(9 \%)$ & $11(32 \%)$ & $19(58 \%)$ \\
$(\mathrm{n}=33)$ & & \\
\hline
\end{tabular}

